\title{
Promoção da saúde mental de professores no contexto da pandemia do novo Coronavírus
}

\author{
Káren Maria Rodrigues da Costa ${ }^{1}$ \\ Hysla Magalhães de Moura² \\ Cássio Eduardo Soares Miranda ${ }^{3}$ \\ Camilla Vieira de Figueiredo ${ }^{4}$
}

\begin{abstract}
Resumo: A área da educação tem sofrido modificações significativas em virtude da atual problemática de saúde pública, conhecida como a pandemia do novo Coronavírus. Grande parte dos professores precisaram se adaptar ao ensino remoto emergencial como uma estratégia para o cumprimento de seus planos curriculares, o que já mostrou ter ocasionado aumentos nos níveis de ansiedade, estresse e depressão dessa categoria profissional. Nesse sentido, o presente estudo objetivou descrever a experiência de uma psicóloga junto a um grupo de docentes do ensino básico. Na oportunidade, buscouse debater coletivamente aspectos relacionados à saúde mental desses profissionais no contexto da pandemia e da consequente adaptação à nova modalidade de ensino remoto. Especificamente, promoveu-se dois encontros online, dos quais participaram profissionais de duas escolas do estado do Piauí. Como resultados, estima-se que os encontros proporcionaram um momento de escuta aos educadores, assim como de construção de estratégias de promoção de seu bem-estar. Confia-se que este relato de experiência possa servir de subsídio para a criação de futuras propostas interventivas voltadas para docentes, além de que tenha viabilizado um espaço de fala, de ressignificação dos desafios e de construção de estratégias para lidar com os mesmos.
\end{abstract}

Palavras-chave: Pandemia. Saúde mental. Professor. Ensino remoto.

\section{Promotion of teachers' mental health in the context of the new Coronavirus pandemic}

\begin{abstract}
The area of education has undergone significant changes due to the current public health problem, known as the new Coronavirus pandemic. Most teachers needed to adapt to remote emergency teaching as a strategy to comply with their curricular plans, which has already shown to have caused
\end{abstract}

\footnotetext{
${ }^{1}$ Psicóloga e Mestra em Saúde e Comunidade pela Universidade Federal do Piauí. E-mail: karen.r.costa@hotmail.com ; ORCID iD: https://orcid.org/0000-0003-0417-6575.

${ }^{2}$ Psicóloga, Mestra e Doutoranda em Psicologia Social pela Universidade do Estado do Rio de Janeiro. E-mail: hyslamagalhaes@gmail.com; ORCID iD: https://orcid.org/0000-0002-5866-5799.

${ }^{3}$ Professor Permanente do Programa de Pós-graduação em Saúde e Comunidade e da RENASF da Universidade Federal do Piauí. Doutor em Psicologia pela Universidade Federal do Rio de Janeiro e Doutor em Letras pela Universidade Federal de Minas Gerais. E-mail: cassioedu@ufpi.edu.br; ORCID iD: https://orcid.org/0000-00028990-1205.

${ }^{4}$ Psicóloga, Mestra e Doutoranda em Psicologia Social pela Universidade Federal da Paraíba. E-mail: camillafigueir@gmail.com; ORCID iD: https://orcid.org/0000-0001-9780-9831.
} 


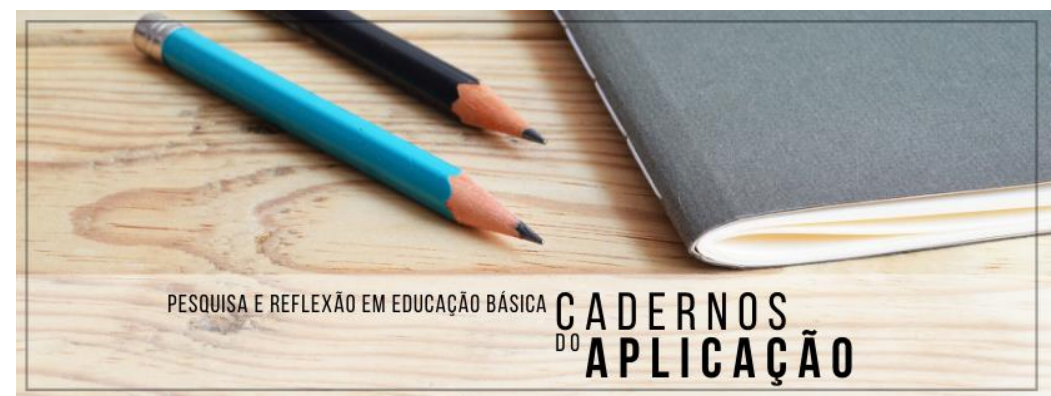

Cadernos do Aplicação

https://seer.ufrgs.br/CadernosdoAplicacao

Publicação Ahead of Print

ISSN 2595-4377 (online)

Porto Alegre | jul-dez. 2021 | v.34 | n.2

increases in the levels of anxiety, stress, and depression in this professional category. In this sense, the present study aimed to describe the experience of a psychologist with a group of teachers of basic education. On the occasion, we sought to collectively discuss aspects related to the mental health of these professionals in the context of the pandemic and the consequent adaptation to the new modality of remote education. Specifically, two online meetings were held, attended by professionals from two schools in the state of Piaui. As a result, it is estimated that the meetings provided an opportunity for educators to talk, as well as to build strategies to promote their well-being. It is hoped that this experience report can serve as input for the creation of future interventional proposals aimed at teachers, in addition to having enabled a space for speech, giving new meaning to challenges, and building strategies to deal with them.

Keywords: Pandemic. Mental health. Teacher. Remote classes.

\title{
Promoción de la salud mental de los docentes en el contexto de la nueva pandemia de Coronavirus
}

\begin{abstract}
Resumen: El área de educación ha experimentado cambios importantes debido al problema de salud pública actual, conocido como la nueva pandemia de Coronavirus. La mayoría de los docentes necesitaron adaptarse a la enseñanza a distancia de emergencia como estrategia para cumplir con sus planes curriculares, lo que ya ha demostrado haber provocado incrementos en los niveles de ansiedad, estrés y depresión en esta categoría profesional. En este sentido, el presente estudio tuvo como objetivo describir la experiencia de un psicólogo con un grupo de docentes de educación básica. En la ocasión, se buscó discutir colectivamente aspectos relacionados con la salud mental de estos profesionales en el contexto de la pandemia y la consecuente adaptación a la nueva modalidad de educación a distancia. En concreto, se realizaron dos encuentros en línea, a los que asistieron profesionales de dos escuelas del estado de Piauí. Como resultado, se estima que las reuniones brindaron una oportunidad para que los educadores hablen, así como para construir estrategias para promover su bienestar. Se espera que este relato de experiencia pueda servir como insumo para la creación de futuras propuestas intervencionistas dirigidas a los docentes, además de haber habilitado un espacio para el discurso, resignificando a los desafios y construyendo estrategias para enfrentarlos.
\end{abstract}

Palabras clave: Pandemia. Salud mental. Profesor. Enseñanza remota.

\section{Introdução}

A pandemia do novo Coronavírus (COVID-19) é a maior emergência de saúde pública que a comunidade internacional tem enfrentado nas últimas décadas. Além das preocupações quanto à saúde física, ela tem trazido apreensões quanto ao sofrimento psicológico que pode ser vivenciado pela população geral (SCHMIDT et al., 2020). Assim, esta situação de 
calamidade pública representa um desafio sem precedentes para a sociedade moderna. Diante desta conjuntura, a abordagem de temas relacionados à saúde mental torna-se crucial (MALLOY-DINIZ et al., 2020).

Nesse cenário pandêmico, muitas atividades tiveram de ser suspensas na tentativa de reduzir a proliferação da COVID-19, dentre elas destaca-se a suspensão das aulas presenciais. Durante esse período, para que crianças, adolescentes e adultos sofressem o menor impacto possível em seu processo de aprendizagem, uma modalidade de ensino passou a estar presente no cotidiano de muitos estudantes no cenário nacional e internacional, sendo esta modalidade o ensino remoto emergencial.

De acordo com Hodges et al. (2020), o ensino remoto emergencial configura-se como uma mudança temporária da entrega de conteúdos curriculares para uma forma de oferta alternativa em virtude da situação de calamidade pública. Esta envolve o uso de soluções de ensino totalmente remotas para as aulas previamente elaboradas no formato presencial. Tais estratégias podem ser utilizadas para momentos híbridos ao longo da crise em função do retorno parcial às aulas e do quantitativo de alunos. Além disso, esses recursos possuem duração delimitada pelo tempo em que essa crise se mantiver.

Em vista disso, muitos professores passaram a se adaptar a esse novo contexto de aulas não presenciais, se dedicando, por exemplo, a aprender a usar ferramentas digitais. Ao colocar em prática este modelo de ensino, foi possível verificar a emergência de alguns desafios. Dentre eles, podemos citar os problemas de ordem emocional, os quais têm afetado tanto docentes quanto alunos (TODOS PELA EDUCAÇÃO, 2020).

Um estudo realizado pelo Instituto Península (2020), que ouviu 2.400 professores da educação básica no mês de maio de 2020, constatou que $67 \%$ dos professores demonstraram ansiedade, $38 \%$ cansaço e $36 \%$ tédio. Ademais, verificou-se que ministrar aulas remotas em contexto doméstico era uma situação inédita para $88 \%$ dos professores, sendo que $83,4 \%$ destes não se sentiam preparados para tal (INSTITUTO PENÍNSULA, 2020). Em outra pesquisa realizada de forma online com 9.000 professores, foi possível verificar o comprometimento dessa modalidade de trabalho na saúde mental dos docentes (SALAS, 2020).

Ao que parece, apresentar propostas que abordem a promoção da saúde mental de professores, por meio de ações que estimulem as potencialidades de cada um (ou do grupo) em 
busca de fortalecimento de aspectos saudáveis, é essencial (ESTANISLAU; BRESSAN, 2014), especialmente no cenário atual. Portanto, investir na saúde mental de professores e gestores de escolas se faz fundamental, tendo em vista as demandas e os desafios que as aulas remotas impõem ao contexto escolar.

\section{Objetivo}

O presente trabalho teve como objetivo apresentar a experiência de intervenção realizada por uma psicóloga com um grupo de docentes do ensino básico. Na oportunidade, buscou-se debater coletivamente aspectos relacionados à saúde mental desses profissionais no contexto atual da pandemia e da consequente adaptação à nova modalidade de ensino remoto.

\section{Método}

Esse trabalho utiliza abordagem qualitativa descritiva, do tipo relato de experiência, apresentando a vivência de uma psicóloga junto a um grupo de professores que passaram a atuar de forma online (ensino remoto) em razão da pandemia do novo Coronavírus.

De acordo com Richardson (2012), a pesquisa qualitativa caracteriza-se pela busca de uma compreensão detalhada dos significados e das características situacionais apresentadas pelos respondentes. No que se refere ao relato de experiência, trata-se de um tipo de pesquisa de cunho social que envolve a atuação e a vivência de um pesquisador. Assim, este profissional toma como base tanto as observações quanto as hipóteses e impressões das situações ocorridas no decorrer da experiência (LOPES, 2012).

A psicóloga em questão experienciou dois momentos com os professores, os quais ocorreram no primeiro semestre de 2020. O trabalho desenvolvido pela psicóloga contou com a participação de professores de duas escolas situadas no estado do Piauí, especificamente uma escola estadual, localizada na zona urbana do município de José de Freitas (escola 1), e uma escola municipal, situada na zona rural de Teresina (escola 2). Os encontros com os professores foram realizados em dois dias. 


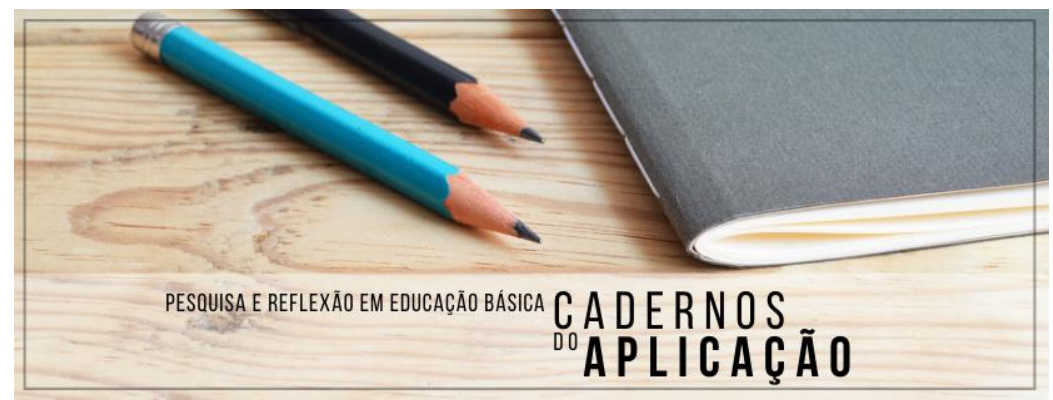

Cadernos do Aplicação

https://seer.ufrgs.br/CadernosdoAplicacao

Publicação Ahead of Print

ISSN 2595-4377 (online)

Porto Alegre | jul-dez. 2021 | v.34 | n.2

O primeiro encontro ocorreu no dia 04 de julho, no turno da manhã, e foi voltado para os profissionais da escola 1. Esse encontro durou aproximadamente três horas e dele participaram professores do $1^{\circ}$ ao $3^{\circ}$ ano do Ensino Médio. $\mathrm{O}$ segundo encontro foi realizado no dia 13 de julho, e foi voltado para os profissionais da escola 2, tendo participado durante o turno da manhã professores do $6^{\circ}$ ao $9^{\circ}$ ano do Ensino Fundamental II, funcionários e coordenadores da escola, e durante o turno da tarde professores do $1^{\circ}$ ao $5^{\circ}$ ano do Ensino Fundamental I. Ambas as vivências tiveram duração de três horas cada.

Os encontros ocorreram por meio de uma plataforma digital e as mediações foram realizadas pelos coordenadores pedagógicos e diretores de cada escola. Tais vivências tiveram o seguinte tema central: "Educação e saúde mental: vamos conversar sobre isso?". A apresentação da temática ocorreu por meio de slides e a interação estabelecida entre a psicóloga e os participantes se deu via chat e áudio. Os resultados dessas vivências serão apresentados a seguir, sendo eles organizados em dois tópicos: 1) Saúde mental dos professores durante as aulas remotas; e 2) Docentes: como cuidar de sua saúde mental em tempos de pandemia.

\section{Resultados e discussão}

\subsection{Saúde mental dos professores diante da modalidade de trabalho remoto}

Inicialmente, a psicóloga se apresentou aos participantes, enfatizando sua formação e experiência para que, de fato, os mesmos pudessem entender o lugar de fala da profissional. Assim, a facilitadora mencionou que possuía seis anos de experiência como psicóloga, já havia atuado na área da clínica, assistência social e atenção básica, e atualmente exercia a função de psicóloga escolar no âmbito da educação especial.

A profissional teve como foco possibilitar o diálogo entre os professores a fim de compreender como estava a saúde mental da equipe docente em virtude das aulas remotas adotadas durante a pandemia. Nesse sentido, buscou-se identificar os pensamentos, sentimentos e comportamentos dos professores no contexto das aulas remotas, assim como a maneira como eles estavam lidando com as demandas que surgiram em decorrência dessa nova modalidade de ensino. 
Verificou-se que esse cenário de aulas remotas apresentou diversos desafios para os professores, principalmente de ordem emocional, como pode ser verificado nas falas a seguir: "Inicialmente fiquei muito abalada, não pelo excesso de trabalho em si, mas pelo fato da não participação dos alunos, mas no momento retornei ao equilíbrio" (docente na escola 1); "É um momento novo, de insegurança, medo e várias emoções. Porém, um momento em que podemos descobrir outras potencialidades que muitas vezes a rotina não nos proporcionava enxergar" (docente na escola 2).

Os profissionais destacaram o aumento de sentimentos como medo, raiva, frustração, insegurança, estresse, ansiedade, cansaço e insônia. Os docentes discorreram ainda sobre outras situações desafiadoras que estavam tendo que manejar, a exemplo de dificuldades técnicas no acesso à internet e ao uso de plataformas digitais, além da dupla jornada de trabalho, visto que que alguns deles, além de realizarem as atividades inerentes à profissão, precisavam auxiliar seus filhos nas atividades escolares e desempenhar tarefas domésticas.

Outro aspecto mencionado pelos docentes e que tem afetado a sua saúde mental referese às cobranças internas dos próprios docentes em relação à aprendizagem dos alunos. Tais cobranças ficaram explícitas por meio das falas: "Tenho muita preocupação com o pouco retorno. Acredito que precisamos ver como alcançar um público maior" (docente na escola 1); "Muito preocupada devido ao pouco retorno de nossos alunos" (docente na escola 1).

Este ponto foi abordado pela facilitadora enfatizando que as exigências são grandes inimigas dos docentes. A partir das falas dos professores nos encontros foi possível verificar que os mesmos se cobravam por circunstâncias que estavam além de seu alcance, como, por exemplo, o aluno não ter acesso à internet, não dispor de um dispositivo móvel para acessar as aulas ou, ainda, de este recurso ser usado por outros membros da família, dificultando o acesso do estudante quando necessário.

Diante desses elementos, a facilitadora lançou a seguinte provocação aos participantes: "Então, o que vocês fazem diante destas questões? Paralisam-se diante da situação ou buscam soluções criativas para superá-las?”. Os profissionais foram incentivados a refletir sobre o seu contexto e suas possibilidades e comentaram sobre a necessidade de reinventar a sua atividade profissional a cada momento. Alguns professores relataram que a nova conjuntura possibilitou a ressignificação dos obstáculos enfrentados, favorecendo a criação de novas formas de 


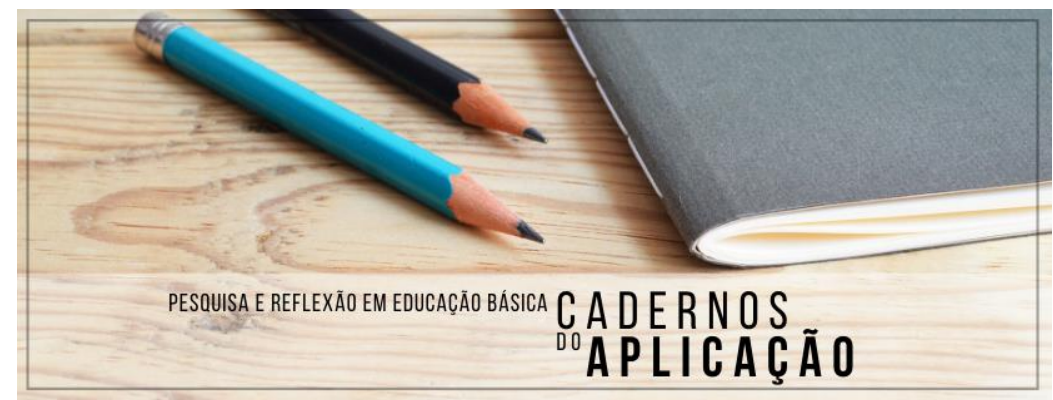

Cadernos do Aplicação

https://seer.ufrgs.br/CadernosdoAplicacao

Publicação Ahead of Print

ISSN 2595-4377 (online)

Porto Alegre | jul-dez. 2021 | v.34 | n.2

promoção do processo de ensino-aprendizagem, como, por exemplo, a utilização de jogos e aplicativos digitais pelos alunos em atividades extraclasse, além da descoberta de possibilidades de promoção de sua própria saúde física e emocional, como vivenciar mais momentos de lazer com a família e realizar atividades físicas.

Cabe enfatizar que aceitar as dificuldades e buscar caminhos alternativos possíveis dentro do cenário atual têm se configurado como estratégias reconfortantes para os professores. Assim, é certo que o trabalho pedagógico deve ser planejado e executado com eficiência e intencionalidade. No entanto, é necessário que os profissionais também reconheçam e aceitem os seus limites pessoais e se orgulhem do papel que estão desenvolvendo para a manutenção do processo de aprendizagem de seus discentes, mesmo diante da realidade desafiadora imposta pela pandemia atual (SALAS, 2020).

\subsection{Docentes: como cuidar da saúde mental em tempos de pandemia}

Para tratar do aspecto da saúde mental em tempos de pandemia, a facilitadora discutiu com os profissionais algumas recomendações para que pudessem desenvolver estratégias de promoção e manutenção da saúde mental. Na oportunidade, a psicóloga enfatizou que essas informações não poderiam ser encaradas como uma "receita de bolo", tendo em vista que o momento atual solicitava que ferramentas e estratégias fossem construídas em parceria com todos os atores envolvidos no trabalho. Para que os professores pudessem desenvolver em maior medida a sua saúde mental, discutiu-se a importância de incorporar três importantes passos em suas rotinas, sendo eles: o "espaço", o "tempo" e o "tempo para nós".

Segundo Coletti (2020), o "espaço" refere-se à organização do local de trabalho, de modo que é fundamental que este seja arejado, organizado e munido dos materiais necessários para lecionar, tais como livros, cadernos, computador, dentre outros. O "tempo", por sua vez, está relacionado à reorganização da rotina diária, o que inclui atividades como dispor de horários para cuidar dos filhos e da casa e para planejar as propostas pedagógicas a serem trabalhadas com os alunos, por exemplo. Por fim, o "tempo para nós" nos remete às atividades que o docente considera prazerosas para si, podendo, assim, contribuir para o seu bem-estar pessoal. 


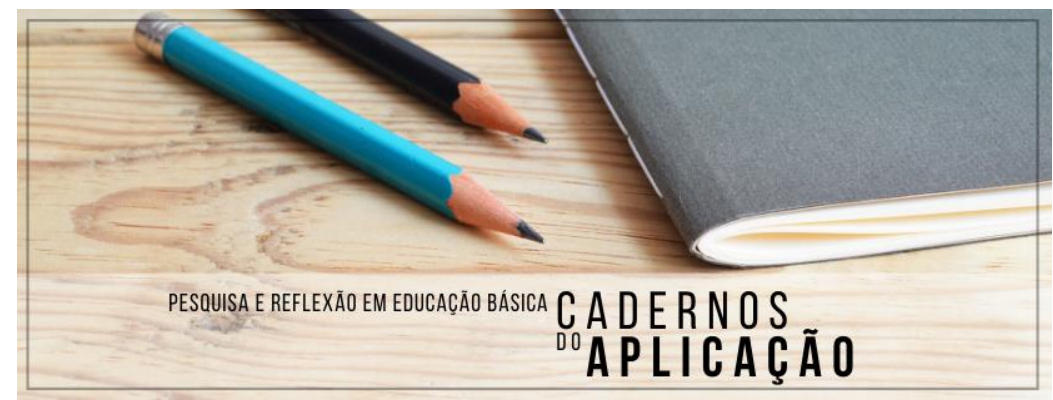

Cadernos do Aplicação

https://seer.ufrgs.br/CadernosdoAplicacao

Publicação Ahead of Print

ISSN 2595-4377 (online)

Porto Alegre | jul-dez. 2021 | v.34 | n.2

Outros pontos mencionados durante os encontros foram a necessidade de estabelecer uma rotina diária, de compartilhar sentimentos, de possuir uma rede de apoio social, de evitar o consumo excessivo de notícias que possam ativar ansiedades e desconfortos emocionais e de procurar desenvolver competências socioemocionais, como a regulação emocional. As competências socioemocionais referem-se às capacidades individuais que se manifestam nos modos de pensar, sentir e nos comportamentos ou atitudes para se relacionar consigo mesmo e com os outros, estabelecer objetivos, tomar decisões, regular e expressar as emoções e enfrentar situações adversas ou novas (MACÊDO; SILVA, 2019).

Em se tratando particularmente desta última modalidade de habilidade mencionada, a resiliência ganha especial destaque, uma vez que possibilita que o indivíduo mantenha ou recupere sua saúde mental mesmo diante de situações adversas como a atual (HERRMAN et al., 2011). Frente ao exposto, confia-se que buscar desenvolver a resiliência pode ser uma estratégia basilar para que os docentes possam lidar com as dificuldades que emergem durante o ensino remoto.

Ao final dos encontros, a facilitadora enfatizou a importância da promoção da saúde mental dos docentes e de todos os atores envolvidos no cotidiano escolar, discutindo que desenvolver saúde mental reduz significativamente a probabilidade do aparecimento de quadros como depressão, ansiedade e esgotamento mental. Além disso, discutiu-se que o cuidado com o outro, no contexto das relações com os escolares, requer primariamente o autocuidado.

\section{Conclusão}

Este trabalho teve como objetivo apresentar a experiência de uma psicóloga com um grupo de docentes do ensino básico sobre a importância do desenvolvimento da saúde mental em tempos de pandemia. Confia-se que abordar estratégias que promovam o bem-estar psicológico em meio a situações de calamidade pública como a atual seja fundamental, considerando que tais situações afetam não somente a saúde física, mas também psicológica. Sobre esse aspecto, a literatura vem apontar que os estados emocionais podem exercer influência sobre o sistema imunológico (RINALDI; CANTO; CHAVES, 2019), de modo que 


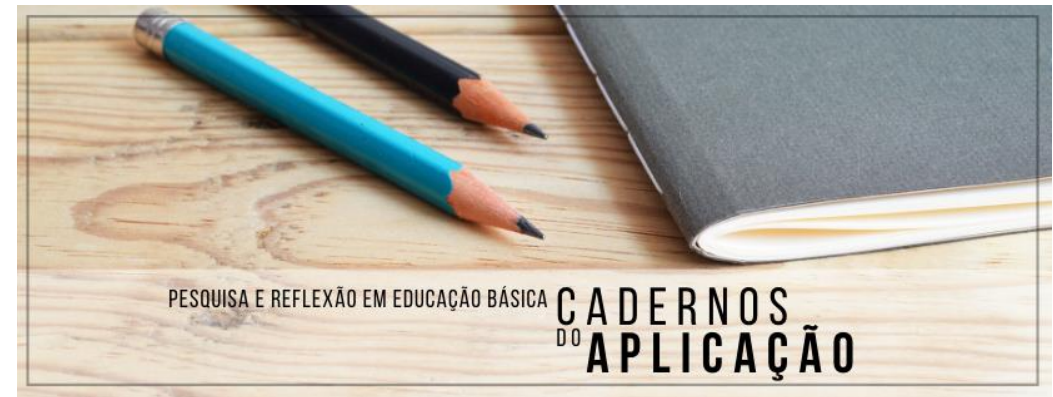

Cadernos do Aplicação https://seer.ufrgs.br/CadernosdoAplicacao

Publicação Ahead of Print

ISSN 2595-4377 (online)

Porto Alegre | jul-dez. 2021 | v.34 | n.2

se pode supor que o bem-estar subjetivo joga um papel protetivo importante no desenvolvimento e manutenção da saúde física e mental.

Em vista do exposto, acredita-se que o presente relato de experiência pode servir de insumo para a criação de propostas interventivas futuras direcionadas para docentes, viabilizando não apenas um espaço de fala coletiva e colaborativa sobre as variadas dificuldades que os professores têm enfrentado durante a pandemia, como também a ressignificação desses desafios e a construção de estratégias para lidar com os mesmos.

Apesar das importantes contribuições, é certo que este trabalho não está isento de limitações. Pode ser citado, por exemplo, o fato de que participaram dos encontros apenas professores do ensino básico. Nesse sentido, sugere-se que estudos futuros ampliem essa discussão a outros níveis educacionais e contextos geográficos, contemplando também professores do ensino superior e da pós-graduação. Alternativamente, sugere-se o desenvolvimento de pesquisas voltadas para a criação de medidas interventivas direcionadas a potencializar aspectos positivos dos professores, no intuito de torná-los mais aptos para enfrentar as adversidades e seus possíveis desdobramentos psicossomáticos.

\section{Referências}

COLETTI, Selene. Como o professor faz home office?. Revista Nova Escola, 2020. Disponível em: https://novaescola.org.br/conteudo/19051/como-professor-faz-home-office. Acesso em: 09 julho, 2020.

ESTANISLAU, Gustavo; BRESSAN, Rodrigo Affonseca. Saúde Mental na Escola: o que os educadores devem saber. Porto Alegre: Artmed, 2014.

HERRMAN, Helen; STEWART, Donna; DIAZ-GRANADOS, Natalia; BERGER, Elena; JACKSON, Beth; YUEN, Tracy. What is resilience?. The Canadian Journal of Psychiatry, v. 56, n. 1, p. 258-265, 2011.

HODGES, Charles; MOORE, Stephanie; LOCKEE, Barb; TRUST, Torrey; BOND, Aaron. The difference between emergency remote teaching and online learning. EDUCAUSE Review, 2020. Disponível em: https://er.educause.edu/articles/2020/3/the-difference-betweenemergency-remote-teaching-and-online-learning. Acesso em: 09 julho, 2020.

INSTITUTO PENÍNSULA. Sentimento e percepção dos professores brasileiros nos diferentes estágios do coronavírus no Brasil. Maio de 2020. Disponível em: https://www.institutopeninsula.org.br/wp-content/uploads/2020/03/Pulso-Covid-19_Instituto-Peni\%CC\%81nsula.pdf. Acesso em: 09 julho, 2020. 


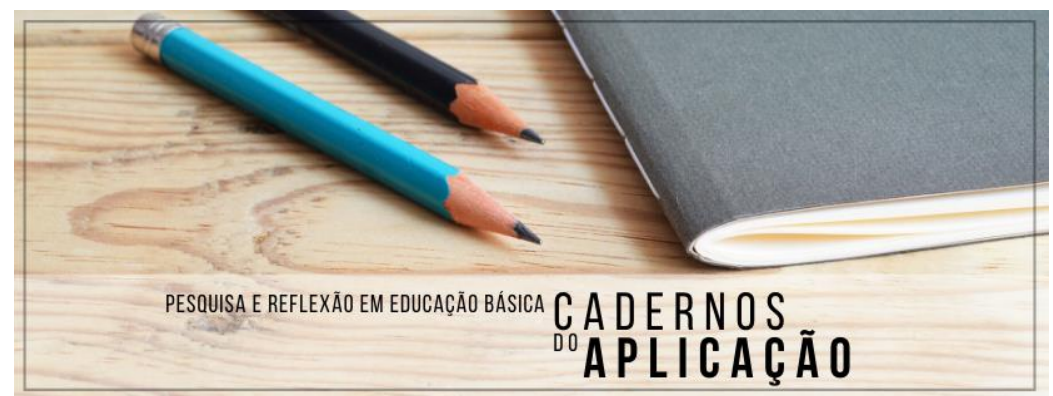

Cadernos do Aplicação https://seer.ufrgs.br/CadernosdoAplicacao

Publicação Ahead of Print

ISSN 2595-4377 (online)

Porto Alegre | jul-dez. 2021 | v.34 | n.2

LOPES, Marcos Venícius de Oliveira. Sobre estudos de casos e relatos de experiências. Revista da Rede de Enfermagem do Nordeste, v. 13, n. 4, p. 1-2, 2012.

MACÊDO, José Wilker de Lucena; SILVA, Anielson Barbosa da. Construção e Validação de uma Escala de Competências Socioemocionais no Brasil. Revista Psicologia: Organizações e Trabalho, v. 20, n. 2, p. 965-973, 2019.

MALLOY-DINIZ, Leandro Fernandes; COSTA, Danielle de Souza; LOUREIRO, Fabiano; MOREIRA, Lafaiete; SILVEIRA, Brenda Kelly Souza et al. Saúde mental na pandemia de COVID-19: considerações práticas multidisciplinares sobre cognição, emoção e comportamento. Debates em Psiquiatria: Associação Brasileira de Psiquiatria, v. 10, n. 2, p. 46-68, 2020.

RICHARDSON, Roberto Jarry. Pesquisa Social: métodos e técnicas. São Paulo: Editora Atlas, 2012.

RINALDI, Juciclara; CANTO, Gabrielle do; CHAVES, Márcia Lorena Fagundes. Better satisfaction with life is associated with normal immune profile (CD4/CD88 ratio) - and depend on the sucessful aging status - in older Brazilian individuals. International Journal of Aging Research, v. 2, n. 1, p. 1-9, 2019.

SALAS, Paula. Ansiedade, medo e exaustão: como a quarentena está abalando a saúde mental dos educadores. Nova Escola, 2020. Disponível em: https://novaescola.org.br/conteudo/19401/ansiedade-medo-e-exaustao-como-a-quarentenaesta-abalando-a-saude-mental-dos-educadores. Acesso em: 04, agosto, 2020.

SCHMIDT, Beatriz; CREPALDI, Maria Aparecida; BOLZE, Simone Dill Azeredo; NEIVASILA, Lucas; DEMENECH, Lauro Miranda. Saúde mental e intervenções psicológicas diante da pandemia do novo coronavírus (COVID-19). Estudos de Psicologia, v. 37, n. 1, p. e200063, 2020.

TODOS PELA EDUCAÇÃO. Nota técnica: Ensino a distância na educação básica frente à pandemia da Covid-19. Todos pela Educação, 2020. Disponível em: https://www.todospelaeducacao.org.br/_uploads/_posts/425.pdf?1730332266=\&utm_source= conteudo-nota\&utm_medium=hiperlink-download. Acesso em: 04, agosto, 2020.

Data de submissão: 12/01/2021

Data de aceite: $30 / 03 / 2021$

DOI: https://doi.org/10.22456/2595-4377.110618 